\title{
Insertion/Deletion Polymorphism of the Angiotensin Converting Enzyme Gene in Coronary Artery Disease in Southern Turkey
}

\author{
Esmeray Acartürk*, Gülen Attila ${ }^{\dagger}$ Abdi Bozkurt, Onur Akpınar, Selçuk Matyar ${ }^{\dagger}$ and Gülşah Seydaoğlu* \\ Çukurova University, School of Medicine, Department of Cardiology, 01330 Adana, Turkey \\ "Çukurova University, School of Medicine, Department of Biochemistry, 01330 Adana, Turkey \\ Çukurova University, School of Medicine, Department of Biostatistics, 01330 Adana, Turkey
}

Received 9 March 2005, Accepted 12 April 2005

\begin{abstract}
Genetic factors are important in the pathogenesis of coronary artery disease (CAD). Angiotensin converting enzyme (ACE) gene insertion(I)/deletion(D) polymorphism is one of the genetic factor found to be related with CAD. We investigated the association between I/D polymorphism of the ACE gene and the presence of CAD. Threehundred and seven patients (187 males and 120 females, aged between 35 80, mean $54.3 \pm 9.8$ years) who underwent diagnostic coronary angiography were included in the study. ACE I/D polymorphism was detected by polymerase chain reaction. Of the 307, 176 had CAD. The most frequently observed genotype in all subjects was ID (47.9 \%). However, in patients with CAD the frequency of II genotype was lower whereas DD genotype was higher compared to the controls $(p<0.05)$. The number of $D$ allele carrying subjects were also higher $(p<0.05)$ in CAD patients. The logistic regression analysis indicated that the $\mathrm{ACE} D$ allele is an independent risk factor (odds ratio $=1.48,95 \% \mathrm{CI}=1.01$ $2.18, p<0.05$ ). In conclusion, the I/D polymorphism of ACE gene (carrying $D$ allele) is an independent risk factor for CAD in the studied Turkish population.
\end{abstract}

Keywords: ACE, Allele, Coronary artery disease, Gene polymorphism, Southern Turkey

\section{Introduction}

Coronary artery disease (CAD) is a multifactorial disease for which hyperlipidemia, hypertension, smoking, diabetes mellitus (DM) and family history are important risk factors. The renin-

\footnotetext{
* To whom correspondence should be addressed. Phone/Fax: +90 3223386933 (work), +90 3223992291 (home) E-mail: kanarya@cu.edu.tr
}

angiotensin system has an important role in cardiovascular physiology. Angiotensin -I- converting enzyme (ACE) also involves in many pathological conditions including vasoconstriction, coronary thrombosis, heart failure and ventricular remodelling (Dzau, 1994). The ACE gene, located at chromosome17q23 contains a polymorphism in intron 16 of an insertion (I) or deletion (D) of a 287 pair Alu repeat sequence which results in three genotypes as II, DD and ID (Mattei et al., 1989; Rigat et al., 1992). The relation between ACE gene polymorphism (DD genotype) and CAD first has been reported by Cambien et al. (1992). Since then numerous studies have been done to evaluate the relationship (Wang et al., 1996; Gardemann et al., 1998; Ferrieres et al., 1999; Eichner et al., 2001). A large case-control study showed a strong association between ACE $\mathrm{D}$ allele with the risk of CAD (Gardemann et al., 1998). In a group of patients living in Turkey an association has also been found (Akar et al., 1998). However some studies have shown no such associations (Friedl et al., 1995; Ferrieres et al.,1999; Pfohl et al., 1999; Agerholm et al., 2000; Canavy et al., 2000). We investigated ACE genotype distribution in patients with angiographically documented CAD, living in Southern Turkey.

\section{Methods}

Patients The study population consisted of 307 patients (187 males and 120 females, aged between 35 - 80, mean $54.3 \pm 9.8$ years ) who were admitted for diagnostic coronary angiography for the assessment of a suspected or confirmed clinical diagnosis of CAD. As a routine procedure, an informed written consent was obtained from all patients before angiography. The study was also approved by the local Ethics Committee.

Risk factors were considered as hypertension, hyperlipidemia, diabetes mellitus, cigarette smoking and family history for CAD. A sustained blood pressure equal or greater than $140 \mathrm{mmHg}$ systolic and $90 \mathrm{mmHg}$ diastolic or using an antihypertensive medication was defined as hypertension (Seventh Report of the Joint National 
Committee on Prevention, Detection, Evaluation and Treatment of High Blood Pressure, 2003). Diabetes mellitus was defined as hyperglycemia, requiring antidiabetic drugs or fasting blood sugar over $126 \mathrm{~g} / \mathrm{dL}$ (American Diabetes Association, the Expert Committee on the diagnosis and classification of diabetes mellitus, 1999). Patients reporting cigarette use during the year prior to examination were considered as smokers. Hyperlipidemia was defined as plasma low-density lipoprotein cholesterol (LDL-C) > $130 \mathrm{mg} / \mathrm{dL}$ or using lipid-lowering drugs at the time of investigation. Hypertriglyceridemia was defined as TG level $>150$ $\mathrm{mg} / \mathrm{dL}$ and low high-density lipoprotein cholesterol (HDL-C) was considered present if the concentration of HDL-C was $<40 \mathrm{mg} / \mathrm{dL}$ according to The Third Report of the National Cholesterol Education Program guidelines. (Executive Summary of The Third Report of The National Cholesterol Education Program (NCEP) Expert Panel on Detection, Evaluation and Treatment of High Cholesterol in Adults , 2001).

Coronary angiography Coronary angiography was performed by Judkins technique and images of coronary tree were obtained in routine, standardized projections. The angiograms were assessed by at least two cardiologists. CAD was diagnosed as $50 \%$ reduction of internal diameter of left anterior descending, right coronary, circumflex artery or their primary branches. Patients without angiographic lesions were considered as the patients without CAD.

Blood chemistry Venous blood samples were collected after 12-h fasting before angiography. Plasma was separated within $4 \mathrm{~h}$ and stored at $-20^{\circ} \mathrm{C}$. Total cholesterol (TC), LDL-C, TG and HDL-C were measured by enzymatic methods by an Olympus 5200 autoanalyzer (Olympus Diagnostica GmbH, Hamburg, Germany).

Determination of ACE I/D polymorphism Genomic DNA from leukocytes was purified according to the method of Miller (Miller et al., 1988). ACE I/D polymorphism was detected by polymerase chain reaction (PCR) by using the primer sequences derived from Zee et al. (1992). The sequences of the primers were chosen such that they flank the targeted region of the genome on the intron 16 of ACE gene (17q23). The template DNA (0.4 mg) was amplified by following primers: (forward) 5'-CTG GAG ACC ACT CCC ATC CTT TCT 3', and (reverse) 5'-GAT GTG GCC ATC ACA TTC GTC AGA T 3'. These primers (10 pmol of each) were added to a mixture containing $5 \mathrm{ml}$ of 10X Cetus buffer ( $\mathrm{pH}$ 8.3), $0.5 \mathrm{mM}$ dNTP (dATP, dCTP, dGTP, dTTP) and 1.0 units of Taq DNA polymerase (Perkin Elmer Cetus). PCR p Program (Perkin Elmer 9600 Thermal Cycler) was initiated in a final total of $50 \mathrm{ml}$ volume with thirty cycles of denaturation for 1 minute at $94^{\circ} \mathrm{C}$, annealing for 1 minute at $58^{\circ} \mathrm{C}$ and primer extension for 1 minute at $72^{\circ} \mathrm{C}$ was applied for amplification. PCR products of ACE gene locus were examined by agarose gel electrophoresis (3\% agarose) at $150 \mathrm{~V}$ for 60 minutes and visualized at room temperature under UV after ethidium bromide staining.

Statistical analysis Statistical analysis was performed with the Statistical Package for the Social Sciences (SPSS), version 9.0, and all values were expressed as mean \pm standard deviation for both genders. Student's t-test and chi-square test were used to evaluate the mean age, plasma lipid profile and other risk factors. A $p$ value
Table 1. Demographic characteristics of the patients with and without coronary artery disease ${ }^{\mathrm{x}}$

\begin{tabular}{lccl}
\hline & $\begin{array}{c}\text { CAD (-) } \\
(\mathrm{n}=131)\end{array}$ & $\begin{array}{c}\mathrm{CAD}(+) \\
(\mathrm{n}=176)\end{array}$ & $\mathrm{p}$ \\
\hline Male/female & $61 / 70$ & $126 / 50$ & 0.000 \\
Hypertension & $48(36.6 \%)$ & $85(48.3 \%)$ & 0.04 \\
Diabetes mellitus & $11(8 \%)$ & $35(20 \%)$ & 0.005 \\
Smoking & $36(28 \%)$ & $83(47 \%)$ & 0.000 \\
Family history & $42(32 \%)$ & $81(46 \%)$ & 0.8 \\
Age & $53 \pm 9$ & $56 \pm 10$ & 0.01 \\
Total C (mg/dL) & $197 \pm 38$ & $212 \pm 48$ & 0.004 \\
HDL-C (mg/dL) & $44 \pm 10$ & $43 \pm 8$ & 0.4 \\
LDL-C (mg/dL) & $120 \pm 31$ & $132 \pm 39$ & 0.003 \\
TG (mg/dL) & $168 \pm 84$ & $177 \pm 106$ & 0.4 \\
Total C/HDL-C & $5.7 \pm 1.1$ & $5.1 \pm 1.4$ & 0.004 \\
\hline
\end{tabular}

${ }^{x}$ Values are expressed as mean \pm standard deviation.

$(+)$, present; (-), absent; CAD, coronary artery disease; HT, hypertension; DM, diabetes mellitus; TC, total cholesterol; HDL$\mathrm{C}$, high density lipoprotein cholesterol; LDL-C, low-density lipoprotein cholesterol; TG triglyceride.

of $<0.05$ was considered significant. Allelic frequencies were calculated by gene-counting method and the genotype distribution with Hardy- Weinberg expectations by a $x^{2}$ test. The differences in subjects with and without CAD were analyzed by a $x^{2}$ and Fisher's exact tests. The stepwise logistic regression analysis was performed for the determination of the independent predictors for CAD and the odds ratios as estimators of relative risk together with their $95 \%$ approximate confidence intervals were calculated to assess the association with and without CAD.

\section{Results}

Table 1 shows the clinical and laboratory characteristics of the patients according to the presence and absence of CAD. Of the 307 subjects, 176 had CAD. Patients with CAD were older and had a significantly greater incidence of hypertension, DM, smoking and also significantly higher concentrations of TC and LDL-C. The most frequently observed genotype in all subjects was ID (47.88\%). ACE genotype distribution was in agreement with the Hardy-Weinberg expectations. The distribution of ACE genotypes in CAD (+) and CAD (-) patients and $\mathrm{D}$ allele carrying subjects are shown in Table 2. II genotype was significantly higher in CAD (-) subjects whereas DD genotype was found to be significantly higher in CAD $(+)$ patients. The number of $\mathrm{D}$ allele carrying subjects were also significantly higher in $\mathrm{CAD}(+)$ cases. The stepwise logistic regression analysis indicated that carrying $\mathrm{D}$ allele of ACE gene was an independent predictor of CAD. Table 3 shows the odds ratios for CAD risk factors. We found the ACE D allele as an independent risk factor (odds ratio $=1.48$, $95 \% \mathrm{CI}=1.01-2.18, p<0.05)$ in our study population. 
Table 2. Angiotensin converting enzyme gene distribution in patients with and without coronary artery disease

\begin{tabular}{ccccc}
\hline & $\begin{array}{c}\text { CAD (-) } \\
\mathrm{n}(\%)\end{array}$ & $\begin{array}{c}\text { CAD }(+) \\
\mathrm{n}(\%)\end{array}$ & OR (CI 95\%) & $\mathrm{p}$ \\
\hline II genotype & $14(10.7)$ & $6(3.4)$ & Ref. & $0.01^{*}$ \\
ID genotype & $66(50.4)$ & $81(46.0)$ & $3.3(1.2-9.0)$ & $0.04^{f}$ \\
DD genotype & $51(38.9)$ & $89(50.6)$ & $1.6(1.0-2.5)$ & 0.01 \\
\hline I allele & $94(35.9)$ & $93(26.4)$ & Ref. & $1.5(1.1-2.2)$ \\
D allele & $168(64.1)$ & $259(73.6)$ & & \\
\hline
\end{tabular}

*ID+DD versus II

- $\mathrm{DD}$ versus II+ID

$(+)$, present; (-), absent; CAD, coronary artery disease.

OR, odds ratio; CI, confidence interval

Table 3. Multivariate logistic regression analysis of coronary artery disease risk factors

\begin{tabular}{lcccccc}
\hline & Coefficient & S.E. & $\mathrm{X}^{2}$ & $\mathrm{p}$ & Odds ratio & $95 \% \mathrm{Cl}$ \\
\hline ACE D allele & 0.394 & 0.197 & 3.987 & 0.046 & 1.483 & $1.01-2.18$ \\
Age & 0.058 & 0.010 & 30.637 & 0.0000 & 1.060 & $1.04-1.08$ \\
Gender (male) & 1.275 & 0.206 & 38.201 & 0.0000 & 3.580 & $2.39-5.37$ \\
Hypertension & 0.685 & 0.201 & 11.628 & 0.0006 & 1.983 & $1.34-2.94$ \\
Diabetes mellitus & 1.088 & 0.289 & 14.192 & 0.0002 & 2.968 & $1.69-5.23$ \\
Smoking & 0.978 & 0.215 & 20.777 & 0.0000 & 2.659 & $1.75-4.05$ \\
LDL-C & 0.009 & 0.003 & 10.259 & 0.0014 & 1.009 & $1.00-1.02$ \\
Constant & -5.763 & 0.755 & 58.202 & 0.0000 & 0.003 & \\
\hline
\end{tabular}

For the total model : $\mathrm{R}^{2}: 0.270$ and likelihood : 694.428

ACE, angiotensin converting enzyme; LDL-C, low density lipoprotein cholesterol.

CI, confidence interval; SE, standard error

\section{Discussion}

Besides very well known risk factors, genetic factors also play a role in the development of coronary artery disease. Genetic factors differ in various populations. Among these, ACE gene polymorphism has most frequently been studied and proposed as a coronary artery disease risk factor. ACE gene polymorphism determines the serum and tissue ACE activity which is high in subjects with DD genotype (Malik et al., 1997). ACE by causing high angiotensin II (Ang II) and low bradykinin levels may increase the risk of CAD (Cambien et al., 1992). Angiotensin II increases the macrophage derived growth factor and platelet derived growth factor which have a role in the genesis of atherosclerosis (Keidal et al., 1993). Furthermore, Ang II leads to LDL- C oxidation and stimulates neutrophil, macrophage and T-lymphocytes (Farber et al., 1990; Keidal et al., 1993). ACE decreases nitric oxide release via the bradykinin-kallikrein system and causes endothelial dysfunction which has also an important role in the genesis of atherosclerosis. Homozygous deletion subset of the ACE I/D polymorphism is associated with deteriorated endothelial function (Mulder et al., 2003).

ACE gene polymorphism has been studied in patients with hypertension, dilated cardiomyopathy and restenosis (Zee et al., 1992; Dzau et al., 1994). Association of the DD genotype of the ACE gene and myocardial infarction (MI) has also been reported in numerous studies (Cambien et al., 1992, Gardemann et al., 1998; Yoshida et al., 1999; Eichner et al., 2001). Cambien et al. (1992) has proposed the ACE I/D polymorphism as a marker of susceptibility to MI. However, the relation between ACE gene polymorphism and CAD has been challenged in different studies. Gardemann et al. have shown a relation between the presence of CAD and ACE D allele in a large case-controlled study (Gardemann et al., 1998). Furthermore, DD genotype of the ACE gene has been reported as a risk factor for the development of early atherosclerosis also in carotid arteries in a Chinese population (Jeng, 2000). There are some other studies in which ACE I/D gene polymorphism has not been found to be associated with the prevalence of CAD (Pfohl et al., 1999; Lindpainter et al., 1995). In a sample in European population with the lowest risk ACE I/D polymorphism has been reported not to be associated with an increased risk of CAD or MI (Ferrieres et $a l ., 1999)$. It has been suggested that the different results from the studies may be due to either the population-specific effect in relation to the ACE gene polymorphism or the lack of the documentation of CAD by means of coronary angiography (Wang et al., 1996; Pfohl et al., 1999).

There are several studies regarding ACE gene polymorphism and CAD in Turkey. Akar and colleagues (Akar et al., 1998) 
have shown an association between $\mathrm{D}$ allele and CAD in patients living in the middle part of Turkey: Similar findings have been found by Isbir and colleagues (Isbir et al., 1999) in patients living in Western Turkey. Whereas a study from South-eastern Turkey and another study from middle part of Turkey have not shown such an association (Tokgozoglu et al., 1997; Nacak et al., 2004). Another study from Western part of Turkey pointed out that ACE gene polymorphism did not play a role in the development of congestive heart failure in $209 \mathrm{CAD}$ patients proven by angiography (Akbulut et al., 2003). However, there were no data on controls in that study. Gurlek et al. (2000) showed that $35 \%$ of 158 patients with CAD who underwent coronary-stenting had ACE I/D polymorphism. The authors also found that ACE I/D polymorphism was significantly associated with the risk of restenosis. However, routine determination of the ACE genotype may not identify patients who are at a higher risk of thrombotic and restenotic events after coronary stenting (Koch et al., 2000).

Our study shows that the DD genotype is a significant predictor of CAD in population living in Southern Turkey. In the present study the frequency of II genotype was significantly low whereas DD genotype was significantly high in patients with CAD compared to the patients with normal coronary arteries proven by angiography. We found the ACE D allele as an independent risk factor (odds ratio $=1.48,95 \% \mathrm{CI}=1.01$ $2.18, p<0.05)$. ACE polymorphism analyzed were in HardyWeinberg equilibrium which indicates that they were normally distributed between the patients with and without CAD.

An association of the ACE DD genotype with the presence of CAD has also been found in Australian population (Wang et al., 1996). On the other hand van Bockxmeer reported that ACE I/D polymorphism did not play a role in the development of CAD or MI in Western Australian Caucasian population (van Bockxmeer et al., 2000). Another study by Jeunemaitre et al. (1997) showed that no association between ACE I/D polymorphism and CAD in 463 Caucasians. Gardemann et al. (1998) found a relation of the ACE I/D gene polymorphism to $\mathrm{CAD}$ and $\mathrm{MI}$ in 2267 male Caucasians and found an increased familial risk of $\mathrm{MI}$ in those carrying the $\mathrm{D}$ allele.

Our findings are not consistent with some other studies coming from Turkey and other countries. This might be due to the genetic heterogenity of the population living in Southern Turkey.

In conclusion, the insertion/deletion polymorphism of ACE gene (carrying D allele) is an independent risk factor for coronary artery disease in the studied Turkish population.

Limitations of the study The nature itself of cross-sectional studies is one of the limitations of this and other case-control studies assessing the influence of single polymorphism in CAD. Another limitations are the sample size and the lack of follow-up.

\section{References}

Agerholm-Larsen, B., Nordestgaard, B. G. and Tybjaerg-Hansen, A. (2000) ACE gene polymorphism in cardiovascular disease: meta-analyses of small and large studies in whites. Arterioscler. Thromb. Vasc. Biol. 20, 484-492.

Akar, N., Aras, O., Omurlu, K. and Cin, S. (1998) Deletion polymorphism at the angiotensin-converting enzyme gene in Turkish patients with coronary artery disease. Scand. J. Clin. Lab. Inves. 58, 491-495.

Akbulut, T., Bilsel, T., Terzi, S., Ciloglu, F., Unal Dayi, S., Sayar, N., Peker, I. and Yesilcimen, K. (2003) Relationship between ACE gene polymorphism and ischemic chronic heart failure in Turkish population. Eur. J. Med. Res. 8, 247-253.

American Diabetes Association, the Expert Committee on the diagnosis and classification of diabetes mellitus. (1999) Diabetes Care 22, 5-19.

Cambien, F., Poirier, O., Lecerf, L., Evans, A., Cambou, J. P., Arveiler, D., Luc, G., Bard, J. M., Bara, L. and Ricard, S. (1992) Deletion polymorphism of the angiotensin-convertingenzyme is a potent risk factor for myocardial infarction. Nature 359, 641-644.

Canavy, I., Henry, M., Morange, P. E., Tiret, L., Poirier, O., Ebagosti, A., Bory, M. and Juhan-Vague, I. (2000) Genetic polymorphisms and coronary artery disease in the south of France. Thromb. Haemost. 83, 212-216.

Dzau, V. J. (1994) Cell biology and genetics of angiotensin in cardiovascular disease. J. Hypertens. 12, 3-10.

Eichner, J. E., Christiansen, V. J., Moore, W. E., Dunn, S. T. and Schechter, E. (2001) Angiotensin I-converting enzyme gene polymorphism in a cohort of coronary angiography patients. Atherosclerosis 154, 673-679.

Executive Summary of The Third Report of The National Cholesterol Education Program (NCEP) Expert Panel on Detection, Evaluation and Treatment of High Cholesterol in Adults (Adult Treatment Panel III). (2001) JAMA. 285, 24862497.

Farber, H. W., Center, D. M., Rounds, S. and Danilov, S. M. (1990) Components of the angiotensin sistem cause release of a neutrophil chemoattractant from cultured bovin and human endhotelial cells. Eur. Heart. J. 11, 100-107.

Ferrieres, J., Ruidavets, J. B., Fauvel, J., Perret, B., Taraszkiewicz, D., Fourcade, J., Nieto, M., Chap, H. and Puel, J. (1999) Angiotensin I-converting enzyme gene polymorphism in a lowrisk European population for coronary artery disease. Atherosclerosis 142, 211-216.

Friedl, W., Krempler, F., Paulweber, B., Pichler, M. and Sandhofer, F. (1995) A deletion polymorphism in the angiotensin converting enzyme gene is not associated with coronary artery disease in the Austrian population. Atherosclerosis 112, 137-143.

Gardemann, A., Fink, M., Sticker, J., Nguyen, Q. D., Humme, J., Katz, N., Tillmanns, H., Hehrlein, F. W., Rau, M. and Haberbosch, W. (1998) ACE I/D polymorphism: presence of the ACE D allele increases the risk of coronary artery disease in younger individuals. Atherosclerosis 139, 153-159.

Gurlek, A., Gulec, S., Karabulut, H., Bokesoy, I., Tutar, E., Pamir, G., Alpman, A., Toydemir, R., Aras, O. and Oral, D. (2000) 
Relation between the insertion/deletion polymorphism of the angiotensin I converting enzyme gene and restenosis after coronary stenting. J. Cardiovasc. Risk 7, 403-407.

Isbir, T., Yýlmaz, H., Agachan, B., Aydin, M. and Isbir, C. S. (1999) Association between angiotensin-converting-enzyme gene polymorphism and coronary artery disease. IUBMB Life 48, 205-207.

Jeng, J. R. (2000) Carotid thickening, cardiac hypertrophy, and angiotensin converting enzyme gene polymorphism in patients with hypertension. Am. J. Hypertens. 13, 111-119.

Jeunemaitre, X., Ledru, F., Battagli, S., Guillanneu, M. T., Courbon, D., Dumont, C., Darmon, O., Guize, L., Guermonprez, J. L., Diebold, B. and Ducimetiere, P. (1997) Genetic polymorphism of the renin-angiotensin system and angiographic extent and severity of coronary artery disease: the CORGENE study. Hum. Genet. 99, 66-73.

Keidar, S., Brook, J. G. and Aviram, M. (1993) Angiotensin-II enhanced lipid peroxidation of low-density lipoprotein. $J$. Am. Physiol. Soc. 8, 245-248.

Koch, W., Kastrati, A., Mehilli, J., Bottiger, C., von Beckerath, N. and Schomig, A. (2000) Insertion/deletion polymorphism of the angiotensin I-converting enzyme gene is not associated with restenosis after coronary stent placement. Circulation. 102, 197-202.

Lindpaintner, K., Pfeffer, M. A., Kreutz, R., Stampfer, M. J., Grodstein, F., LaMotte, F., Buring, J. and Hennekens, C. H. (1995) A prospective evaluation of an angiotensin-convertingenzyme gene polymorphism and the risk of ischemic heart disease. N. Engl. J. Med. 332, 706-711.

Malik, F. S., Lavie, C. J., Mehra, M. R., Milani, R. V. and Re, R. N. (1997) Renin-angiotensin system: Genes to bedside. Am. Heart J. 134, 514-526

Mattei, M. G., Hubert, C., Alhenc-Gelas, F., Roeckel, N., Corvol, P. and Soubrier, F. (1989) Angiotensin I-converting enzyme gene is on chromosom 17. Cytogent. Cell Gene. 51, 1041.

Miller, S. A., Dykes, D. D. and Polesky, H. F. (1988) A simple salting out procedure for extracting DNA from human nucleated cells. Nucleic. Acids. Res. 16,1215.

Mulder, H. J., van Geel, P. P., Schalij, M. J., van Gilst, W. H., Zwinderman, A. H. and Bruschke, A. V (2003) DD ACE gene polymorphism is associated with increased coronary artery endothelial dysfunction: the PREFACE trial. Heart. 89, 557558.

Nacak, M., Davutoglu, U., Soydinc, S., Dinckal, H., Turkmen, S., Erbagci, B., Akcay, M. and Aynacioglu, S. (2004) Association between angiotensin-converting-enzyme gene polymorphism and coronary artery disease in individuals of the South-eastern Anatolian population. Anatol. J. Cardiol. 4, 45-51.

Pfohl, M., Koch, M., Prescod, S., Haase, K. K., Haring, H. U. and Karsch, K. R. (1999) Angiotensin I-converting enzyme gene polymorphism, coronary artery disease and myocardial infarction. An angiographically controlled study. Eur. Heart $J$. 20, 1318-1325.

Rigat, B., Hubert, C., Corvol, P. and Soubrier, F. (1992) PCR detection of the insertion/deletion polymorphism of the human angiotensinconverting enzyme gene (DCPI) (dipepdidylcarboxypepdidase 1). Nucleic. Acids. Res. 20, 1433.

Seventh Report of the Joint National Committee on Prevention, Detection, Evaluation and Treatment of High Blood Pressure. (2003) Hypertension 42, 1206-1252

Tokgozoglu, S. L., Alikasifoglu, M., Atalar, E., Tuncbilek, E., Ovunc, K., Aksoyek, S., Kabakci, G., Anar, B., Unsal, I. and Kes, S. (1997) Angiotensin Converting enzyme gene polymorphism and the risk and extent of ischemic heart disease among Turkish patients. Coron. Artery. Dis. 8, 137-141.

van Bockxmeer, F. M., Mamotte, C. D., Burke, V. and Taylor, R. R. (2000) Angiotensin-converting enzyme polymorphism and premature coronary heart disease. Clin. Sci. 99, 247-251.

Wang, X. L., McCredie, R. M. and Wilcken, D. E. (1996) Genotype distribution of ACE polymorphism in Australian healthy and coronary populations and relevance to myocardial infarction and coronary artery disease. Arterioscler. Tromb. Vasc. Biol. 16, 115-119.

Yoshida, M., Iwai, N., Ohmichi, N., Izumi, M., Nakamura, Y. and Kinoshita, M. (1999) D allele of angiotensin-converting enzyme gene is a risk factor for secondary cardiac events after myocardial infarction. Int. J. Cardiol. 70, 119-125.

Zee, R. Y., Lou, Y. K., Griffiths, L. R. and Morris, B. J. (1992) Association of a polymorphism of the angiotensin I-converting enzyme gene with essential hypertension. Biochem. Biophys. Res. Commun. 184, 9-15. 